\title{
A Question of Value: On the Legality of Using Kyoto Protocol Units under the Paris Agreement
}

\author{
David Rossati \\ Faculty of Law, Vrije Universiteit Amsterdam, Amsterdam, \\ The Netherlands \\ d.rossati@vu.nl
}

\begin{abstract}
The first commitment period of the Kyoto Protocol generated about 4.3 billion Assigned Amount Units (AAUs) and about 180 million Certified Emission Reductions (CERs) for carry-over by Annex I states and potential use as 'overachievements' or offsets to discount emissions under NDCs. The second commitment period may generate additional carry-over units, and there is an estimated 'dormant' amount of about 4.6 billion CERs that could be issued from ongoing CDM projects. To rely on these units risks upsetting the process of trust-building necessary to increase ambition under the Paris Agreement. This article questions the legality of carry-overs but finds that a textual interpretation of the current legal framework under both treaties leaves the matter unresolved. With a more refined legal interpretation, based on the principles of environmental integrity and sound accounting under the Paris Agreement, the article re-evaluates AAUs and CERs under the Agreement, by relying on insights from a social theory of value and the critical studies literature on the political economy of carbon markets. The conclusion is that AAUs cannot be used under the NDC accounting framework, as their formal value of $1 \mathrm{Mt} \mathrm{CO}_{2}$ eq. under the Kyoto Protocol is considerably diminished under the Agreement. As for CERs, their value depends on different social realities related to their issuance. States or the CMA should adopt transparent criteria to select the CERs that are worth transitioning pursuant to the Article 6.4 mechanism. The same conceptual framework of value-attribution can also inform the design and operation of the Article 6 mechanisms and their units in order to attain higher environmental integrity and sound accounting for NDCs.
\end{abstract}




\section{Keywords}

market-based mechanisms - Paris Agreement Article 6 - Kyoto Protocol flexibility mechanisms - units of accounting: Assigned Amount Units (AAUs) - Certified Emission Reductions (CERs) - banked units - carry-over units

\section{1 \\ Introduction}

After almost eight years of hanging in limbo, in October 2020 the Doha Amendment to the Kyoto Protocol entered into force, right at the end date of the second commitment period (2013-2020) it was meant to govern. ${ }^{1}$ The participating Annex I parties are not facing new binding targets, which might suggest that the Kyoto Protocol has entered a twilight zone prior to reaching a state of inactivity or even desuetude. But the fact that this treaty has relied on emission-accounting units ('units' or 'Kyoto Protocol units') ${ }^{2}$ for the functioning of its market-based mechanisms and for ensuring state compliance opens up a space for a continued relevance of these units. This is because they potentially can be used for accounting and compliance under the Paris Agreement, including under the Article 6 mechanisms.

This article considers the legality and consequences of using AAUs 'carried over' from the commitment periods or of CERs created under the Clean Development Mechanism. While the Kyoto Protocol has also generated other types of units, the rationale for focusing on these two types relates, on the one hand, to announced state intentions about reliance on carried-over AAUs, and, on the other hand, to ongoing negotiations over the future of the CDM and its units.

Australia is one state considering using its 'overachievements' from the Kyoto Protocol's commitment periods to offset its emissions towards its NDC goal for 2030. These consist of $128 \mathrm{Mt} \mathrm{CO}_{2}$ eq. $^{3}$ of formally accounted-for carry-over AAUs from the first commitment period and an estimated $303 \mathrm{Mt}$ $\mathrm{CO}_{2}$ eq. of AAUs from the second commitment period. ${ }^{4}$ If applied together,

1 Kyoto Protocol, Decision 1/CMP.8, Doha Amendment to the Kyoto Protocol, FCCC/ $\mathrm{KP} / \mathrm{CMP} / 2012 / 13 /$ Add.1 (2013), Annex I.

2 AAUs are created under Art. 17, CERs under Art. 12, and Emission Reduction Units (ERUS) under Joint Implementation, in Art. 6. The Protocol also creates Removal Units (RMUs) from LULUCF activities.

3 Australian Government, Australia's Emissions Projections 2020, Commonwealth of Australia, 2020, 4, <www.industry.gov.au/sites/default/files/2020-12/australias-emissionsprojections-2020.pdf $>$.

4 Ibid. 
Australia could offset an amount of emissions equal to about 8 o per cent of its emissions for 2020. ${ }^{5}$ Its latest NDC submission claims that 'Australia is on track to meet and beat its 2030 target without relying on past overachievement'. ${ }^{6}$ This, however, does not exclude a future reliance on it should it need to. ${ }^{7}$ The suggestion that such use is possible has been called a 'potentially dangerous precedent' for the Paris Agreement and 'without any legal basis' by a group of Australian law academics, ${ }^{8}$ as it could lead other Annex B countries with surplus AAUs in their accounts to follow suit and alter what might have been an implicit understanding under the NDC framework that no mitigation efforts previous to the first NDC period would be factored in. A similar sentiment was expressed during the COP 25 negotiations when a group of thirty-two parties proposed a set of principles to inform the completion of the Paris Rulebook on market-based mechanisms; one principle calls for a prohibition of 'the use of pre-202O units, Kyoto units and allowances, and any underlying reductions toward Paris Agreement and other international goals. ${ }^{9}$

On the transition of the CDM under Article 6, states at COP 25 were unable to reach agreement on the transfer of CERs issued prior to the expiry of the second commitment period. The final negotiating text on the Article 6.4 mechanism, despite attempting to quantify eligible CERs and CDM projects, did not reflect consensus. ${ }^{10}$ The disagreement was due to the fact that some states were against such a transition while others wanted to maintain support for the past achievements of the CDM in mitigation and sustainable development. ${ }^{11}$

5 These amount to $528.7 \mathrm{Mt} \mathrm{CO}_{2}$ eq.; see Australian Government, Quarterly Update of Australia's National Greenhouse Gas Inventory: March 2020, Commonwealth of Australia, 2020, 3, <www. industry.gov.au/sites/default/files/2020-08/nggi-quarterly-update-march-2020.pdf >.

6 Australian Government, Australia's Nationally Determined Contribution: Communication 2020, 2020, 6 .

7 Ibid., 1.

8 Chloé Farand, 'Australia's Carbon Accounting Plan for Paris Goals Criticised as "Legally Baseless", Climate Home News, 4 March 2020, <www.climatechangenews.com/2020/03/o4/ australias-carbon-accounting-plan-paris-goals-criticised-legally-baseless $/>$.

9 San Jose Principles for High Ambition and Integrity in International Carbon Markets, 14 December 2019, <https://cambioclimatico.go.cr/press-release-leading-countries-setbenchmark-for-carbon-markets-with-san-jose-principles/> (hereinafter San Jose Principles).

10 Draft text on matters relating to Article 6 of the Paris Agreement: Rules, modalities and procedures for the mechanism established by Article 6, paragraph 4, of the Paris Agreement. Proposal by the President - Version 3 of 15 December 2019 1:10 hrs, DT.cma2.i1lb.v3, Annex, paras 72-6 (hereinafter Draft text on Article 6.4 of the Paris Agreement).

11 Matthieu Wemaëre, 'Article 6 Voluntary Cooperation/NDcs', in The Paris Agreement on Climate Change: A Commentary, edited by Geert Van Calster and Leonie Reins (Cheltenham, UK: Edward Elgar Publishing, 2021), 148, 167-8. 
The number of units at stake is significant. The first commitment period of the Kyoto Protocol generated a vast amount of AAUs for carry-over: about 4.3 $\mathrm{Gt} \mathrm{CO}_{2}$ eq. Two gigatons of this is 'hot air' from the Ukraine, with most of the rest being shared among other Economy-in-Transition countries. ${ }^{12}$ As of September 2020, states had formally carried over from the first commitment period to the second only about 5.7 million AAU s. ${ }^{13}$ This transfer is not definitive until the UNFCCC Secretariat publishes a final assessment of greenhouse gas accounting and units for each Annex B party for the second commitment period, affirming how many units can be carried over, following which each party can make carry-over transactions up to the amount identified until the end of the true-up period in late $2023 .{ }^{14}$ Therefore, the relatively small amount of AAUs that has been carried-over so far does not exclude the possibility that Annex B parties will claim part or the entirety of their remaining amounts for carry-over before the end of the true-up period-except for those units that have already been voluntarily cancelled. As for CERs from the first commitment period, there are about 180 million units that could be carried over by states. ${ }^{15}$ So far, states have made carry-over transactions for 137 million CERs. ${ }^{16}$ These are added to CERs issued during the second commitment period, amounting to about 600 million. ${ }^{17}$ In addition, there is an estimated $4.65 \mathrm{Gt}$ $\mathrm{CO}_{2}$ eq. of purported reductions from 'dormant' CDM projects, which could

12 This calculation comes from adding up the amounts of carried-over AAUs and CERs assigned to each country in the following document: UNFCCC Secretariat, Annual compilation and accounting report for Annex B Parties under the Kyoto Protocol, FCCC/KP/CMP/2016/6 (2016), Table 1. For the amount of carried-over AAUs for Ukraine, see UnFCcc Secretariat, Final compilation and accounting report for Ukraine for the first commitment period of the Kyoto Protocol, FCCC/KP/CMP/2017/CAR/UKR (2017), table 2.

13 Subsidiary Body for Implementation, Report of the administrator of the international transaction log under the Kyoto Protocol, FCCC/SBI/2020/INF.11 (2020), para. 34.

14 UNFCCC website, 'FAQ on transactions of Kyoto Protocol units related to the true-up process for the first commitment period of the Kyoto Protocol and on the True-up Period Report template', Q\&A 16, <https://unfccc.int/files/kyoto_protocol/true-up_process/application/ pdf/faqtuptransactions\&report.pdf >.

15 UNFCCC Secretariat, Annual compilation and accounting report for Annex B Parties under the Kyoto Protocol, supra note 12.

16 Subsidiary Body for Implementation, supra note 13, para. 34.

17 UNeP DTU Partnership Website, 'CERs' page, document 'CDM Pipeline Spreadsheet', 2021, $<$ www.cdmpipeline.org/publications/CDMPipeline.xlsm>. CERs can also be voluntarily cancelled from public and private accounts. Cancellations since October 2012 amount to about 85 million, as of August 2021; see CDM Registry Website, document 'Voluntarily cancelled units as at 31 August 2021', 2021, <https://cdm.unfccc.int/sunsetcms/storage/ contents/stored-file-20210901135301485/CDM_Registry_VC_August2021_pub.xlsx>. 
yield additional CERs up to 2020 if project participants decide to request their issuance, for example because favourable market conditions emerge. ${ }^{18}$

These potential carry-over units might be used under the Paris Agreement as a means of accounting for the achievement of NDCs or as fungible equivalents to Internationally Transferred Mitigation Outcomes (IтMOs) and the units of the Article 6.4 mechanism. Such use would risk upsetting the delicate process of trust-building toward higher mitigation ambition under the Paris Agreement, ${ }^{19}$ since claimed overachievements via AAUs or a reliance on CERs might be regarded by other states and the broader public as an attempt to water down the ambition of NDCs. Perceptions of this kind would most likely be grounded on differing notions of the value attached to these units; for example, that carried-over AAUs issued in 2008 should not be valued in the same way as IтMOs, as they reflect different mitigation ambitions. Similarly, CERs stemming from projects whose additionality is contested should not bear the same value as future offset credits under a more rigorous Article 6.4 mechanism, with its requirements of 'overall mitigation in global emissions' and environmental integrity. ${ }^{20}$ The term 'value' is deliberately vague, because an assessment of the legality of the use of Kyoto Protocol units under the Paris Agreement requires a careful analysis of the types of value that are accorded to these units. When the social realities behind the production and circulation of units is taken into account, such an analysis offers insights into the challenges of achieving the transparency and environmental integrity that are required under the Article 6 mechanisms.

Accordingly, in Section 2, I explain why, in the absence of any explicit prohibition in the Paris Rulebook, states would seem to have a discretion to use Kyoto Protocol units under the Paris Agreement. I will show that this interpretation is, however, implausible, by reconstructing how these units assume value and by presenting a teleological interpretation of key obligations of the Paris Agreement emphasizing trust-building among the parties. The upshot is that carried-over AAUs and CERs cannot, under the Agreement, all maintain their formal value of $1 \mathrm{Mt} \mathrm{CO}_{2}$ eq. Section 3 provides the theoretical basis for this argument by engaging with value theories and the critical literature on the political economy of carbon markets which reveals important gaps in the legal scholarship conceptualizing units and their legal nature. The

18 Wemaëre, supra note 11,167 .

19 Lavanya Rajamani and Jutta Brunnée, 'The Legality of Downgrading Nationally Determined Contributions under the Paris Agreement: Lessons from the US Disengagement', 29(3) Journal of Environmental Law 537 (2017).

20 Paris Agreement, art. 6(1) and (4)(d). 
analysis demonstrates the need to identify and apply qualitative distinctions between units of the same kind by factoring in the vast and varied constitutive events surrounding and buttressing the creation and circulation of these units. Section 4 implements this conceptual framework, looking closely at the value-making process for carried-over AAUs and pre-2O21 CERs. I find that carried-over AAUs have lost considerable value since their initial issuance and that the current value of CERs depends on the nuanced realities and impacts of each CDM project. The final section of the article argues that, even without a CMA decision on the matter, states must refrain from using AAUs and must exercise due diligence in using CERs to achieve their NDCs. If this advice is not heeded, the 'normative expectations of progression and highest possible ambition' under the Paris Agreement will be violated ${ }^{21}$ and state practices lacking due diligence in making use of Kyoto Protocol units may be indicative of bad faith in achieving crucial expectations of ambition under the Paris Agreement.

\section{The Legal Framework on the Use of Kyoto Protocol Units under the Paris Agreement}

A literal reading of the measuring, reporting, and verification ${ }^{22}$ framework of the Paris Agreement does not explicitly prohibit Annex B parties from using carried-over AAUS orCERs to demonstrate NDC achievement, including through the Article 6 mechanisms. A necessary starting point for a more in-depth consideration of the issue is the relationship between the Paris Agreement and the Kyoto Protocol. Both instruments complement the UNFCCC, and there is no provision in the Paris Agreement or in the cop decision adopting it indicating how the Agreement relates to the Kyoto Protocol. The provisions of the two treaties do not conflict with each other to any extent that would make it impossible to apply both instruments simultaneously. ${ }^{23}$ This is seen in the fact that the several processes of the Kyoto Protocol have been running in parallel with the Paris Agreement since the entry into force of the latter.

21 Rajamani and Brunnée, supra note 19.

22 This consists of the reporting requirements under the Enhanced Transparency Framework, the accounting rules and guidelines for NDCs, and the still awaited guidelines and modalities on the Article 6 mechanisms. See Benoit Mayer, 'Transparency Under the Paris Rulebook: Is the Transparency Framework Truly Enhanced?', 9(1-2) Climate Law 40 (2019); Meinhard Doelle, 'The Heart of the Paris Rulebook: Communicating NDCs and Accounting for Their Implementation', 9(1-2) Climate Law 3 (2019); and Wemaëre, supra note 11.

23 Vienna Convention on the Law of Treaties, art. 3o(3) and (4). 
It is not unusual in treaty practice for states to refer to rules and other provisions originating in treaty A to prove their compliance with obligations in treaty B, even when the latter does not make explicit reference to the former. ${ }^{24}$ Of course, any 'import' of such a kind will need to be warranted under the framework of treaty B. In the case at hand, the Paris Agreement framework seems to have left an opening for recognizing AAUs and CERS as a material product of treaty obligations, processes, and guidelines under the Kyoto Protocol.

Under the Kyoto Protocol's Mrv framework, Annex B parties are required to incorporate into their National Inventory Reports (NIRS) the 'necessary supplementary information' needed to demonstrate compliance with their targets. ${ }^{25}$ Among the items to be reported are the quantities of all Kyoto Protocol units held in the national registry, including information on the types of transaction that have occurred. ${ }^{26}$ Thus each Annex B party must communicate to the Secretariat its budget of units, including its holdings of carry-over AAUs and CERs. ${ }^{27}$ The information is verified by Expert Review Teams, ${ }^{28}$ and it is this step that gives a form of objectivity and validity to Kyoto Protocol units at the international level. These units, as verified by an international regulatory process, are a material product of Kyoto Protocol treaty obligations.

A potential basis for importing Kyoto Protocol units into the Paris Agreement can be found in the Paris Rulebook's guidance on accounting for NDCs, ${ }^{29}$ as

24 For instance, in a recent wTO dispute Australia successfully used the guidelines adopted under the Framework Convention on Tobacco Control as evidence to justify the compliance of its plain packaging policy on tobacco products with the WTO Agreement on Technical Barriers to Trade, a treaty that does not specify what documents can count as evidence to justify trade-restrictive standards. See Australia-Certain Measures Concerning Trademarks, Geographical Indications and Other Plain Packaging Requirements Applicable to Tobacco Products, Appellate Body Reps, WT/DS435/AB/R and WT/DS441/AB/R (9 June 2020), paras 6.702-6.707.

25 Kyoto Protocol, art. 7(1); and Decision 24/CP.19, Revision of the UNFCCC reporting guidelines on annual inventories for Parties included in Annex I to the Convention, FCCC/CP/2013/10/ Add.3 (2014).

26 Kyoto Protocol, Decision 15/CMP.1, Guidelines for the preparation of the information required under Article 7 of the Kyoto Protocol, FCCC/KP/CMP/2005/8/Add.2 (2006), Annex, paras 1off. For the second commitment period: Kyoto Protocol, Decision 3/CM P.11, Implications of the implementation of decisions 2/CMP.7 to 4/CMP.7 and 1/CMP.8, FCCC/KP/CMP/2015/8/Add.1 (2016), Annex I, II, and III.

27 See, for instance, Australian Government, National Inventory Report 2019, Volume 1, Commonwealth of Australia, 2021, xvi.

28 Kyoto Protocol, art. 8.

29 Paris Agreement, Decision 4/CMA.1, Further guidance in relation to the mitigation section of decision 1/CP.21, FCCC/PA/CMA/2018/3/Add.1 (2019), Annex II (hereinafter Decision 4/CMA.1). 
well as in the CMA's decision on the modalities, procedures, and guidelines for the Enhanced Transparency Framework. ${ }^{30}$ The key provisions concern the methodologies for accounting for emissions and for the progress that parties make in implementing and achieving NDCs. The first item of guidance provides as follows:

(a) Parties account for anthropogenic emissions and removals in accordance with methodologies and common metrics assessed by the IPCC and in accordance with decision 18/CMA.1;

(b) Parties whose nationally determined contribution cannot be accounted for using methodologies covered by IPCC guidelines provide information on their own methodology used, including for nationally determined contributions pursuant to Article 4, paragraph 6, of the Paris Agreement, if applicable;

(c) Parties that draw on existing methods and guidance established under the Convention and its related legal instruments, as appropriate, provide information on how they have done so;

(d) Parties provide information on methodologies used to track progress arising from the implementation of policies and measures, as appropriate. $^{31}$

These provisions allow some discretion, such that a state is enabled to frame its greenhouse gas accounting methodology with a view to integrating and giving relevance to Kyoto Protocol units. The current IPCC guidelines do not include Kyoto Protocol units in the reporting of emission inventories. ${ }^{32}$ However, the reference to methods from 'related legal instruments' encompasses the Kyoto Protocol' accounting requirements, which include the reporting of the budget of units. A similar opening can be found in the ETF rules, where in the section dedicated to methods for preparing the NIR it is stated that 'Each Party may use nationally appropriate methodologies if they better reflect its national

30 Paris Agreement, Decision 18/CMA.1, Modalities, procedures and guidelines for the transparency framework for action and support referred to in Article 13 of the Paris Agreement, FCCC/PA/CMA/2018/3/Add.2 (2019), Annex (hereinafter Decision 18/CMA.1).

31 Decision 4/CMA.1, supra note 29, para. 1, emphasis added.

32 Simon Eggleston, et al. (eds.), 2006 IPCC Guidelines for National Greenhouse Gas Inventories (Hayama, Japan: Institute for Global Environmental Strategies, 2006); Eduardo Calvo Buendia, et al. (eds.), 2019 Refinement to the 2006 IPCC Guidelines for National Greenhouse Gas Inventories (Geneva: IPCC, 2019). 
circumstances and are consistent with the IPCC guidelines.' ${ }^{33}$ Moreover, the rules on the provision of information necessary to track progress made in implementing and achieving NDCs require each party to indicate its accounting approach and to 'provide any definitions needed to understand its NDC under Article 4, including those related to each indicator identified [... and] those related to any sectors or categories defined differently than in the national inventory reports. ${ }^{34}$

These provisions could be read to include the so-called overachievements represented by carried-over AAUs or CERS as a new category in emission accounting toward the implementation and achievement of NDCs. This is what the Australian government, for instance, seems to be claiming when giving recognition to its carried-over AAUs and CERs as overachievements under its NDC 2030 target. $^{35}$

Carried-over AAUS and CERs might also find recognition under the market mechanisms of Article 6. The Paris Rulebook already includes reporting requirements on the methodologies used for ITMOs; here again the language is sufficiently vague to allow for the inclusion of Kyoto Protocol units for the purposes of the 'cooperative approaches' between parties. ${ }^{36}$

A restrictive reading is also possible, such that the above actions would be constrained or excluded. One argument would focus on absence of any explicit provision permitting use of Kyoto Protocol units. Another would be that the MRV framework requires conservative accounting ${ }^{37}$ and also that each party is to justify in detail how any methodological diversion aligns with the conservative approach and is consistent with IPCC guidelines. ${ }^{38}$ The inclusion of overachievement claims via carried-over AAUS or CERs in the accounting methodology for NDC targets could be difficult to justify when taking into account the requirement to 'promote environmental integrity, transparency,

\footnotetext{
33 Decision 18/CMA.1, supra note 30, Annex, para. 22.

34 Ibid., paras. 71 and 73, emphasis added.

35 See Australian Government, Australia's Fourth Biennial Report, Commonwealth of Australia, 2019, 42 and 124 .

36 Decision 18/CMA.1, supra note 30, paras. $75(\mathrm{f})$ and $77(\mathrm{~d})$. The Article 6.2 draft text, however, indicates that ITMOs are 'generated in respect of or representing mitigation from 2021 onwards' (supra note 10, para. $1(\mathrm{e})$ ). As this text is still under negotiation, the legal basis is probably weaker here.

37 Paris Agreement, art. 4(13) and (14).

38 Decision 4/CMA.1, supra note 29, Annex I, para. 5, and Annex II para 1(b); Decision 18/CMA.1, supra note 30 , Annex, paras 74-7.
} 
accuracy, completeness, comparability and consistency, and ensure the avoidance of double counting' in accounting for NDCs. ${ }^{39}$

Furthermore, parties to the Paris Agreement face key obligations of conduct which, read together with preparatory works, point at normative expectations of 'progression and highest possible ambition' from all states in the context of a dynamic differentiation between states over time. ${ }^{40}$ These expectations are not legally binding, ${ }^{41}$ but rather frame a sophisticated process of trust-building among parties which is indispensable to ensure that at least all major emitters align their efforts toward complying with the $1.5^{\circ} \mathrm{C}$ limitation goal, as one of the main objectives of the Paris Agreement. ${ }^{42}$ The achievement of a higher level of trust among parties is, therefore, a necessary goal to consider under a teleological interpretation of key obligations of conduct under the treaty. ${ }^{43}$ MRV rules, including those to be adopted under Article 6, should not be interpreted in a way that risks undermining trust through state practices that affect the reliability of mitigation information collectively assessed at the Global Stocktake. ${ }^{44}$

In order to further illuminate the restrictive approach and its consequences at law, a detailed analysis of Kyoto Protocol units becomes necessary, in terms of what they represent, the types of value attributed to them, and how these entail forms of qualitative distinction among a given type of unit. The next two sections will argue that the claim that AAUs and CERs for carry-over represent overachievement is based on a distorted and limited understanding of their value-making process.

39 Paris Agreement, art. 4(13).

40 Rajamani and Brunnée, supra note 19.

41 However, see Christina Voigt and Felipe Ferreira, "Dynamic Differentiation": The Principles of CвDR-RC, Progression and Highest Possible Ambition in the Paris Agreement', 5(2) Transnational Environmental Law 285 (2016), 302, claiming that the principle of highest possible ambition in submitting new NDCs reflects a due-diligence standard under international law and requires states to act according to the level of risk.

42 Rajamani and Brunnée, supra note 19, 539. Paris Agreement, art. 2(1)(a).

43 When defending the importance of the obligation of conduct requiring parties to 'pursue domestic mitigation measures, with the aim of achieving the objectives of such contributions [NDCs]' under the Paris Agreement, art. 4(2), second sentence, Mayer notes that such obligations are an 'effective tool' to promote increased ambition and the implementation of carbon-mitigation efforts by all parties; see Benoit Mayer, 'Obligations of Conduct in the International Law on Climate Change: A Defence', $27(2)$ Review of European, Comparative and International Environmental Law 130 (2018).

44 See Paris Agreement, art. 13(1), stressing the key purposes of the ETF being 'to build mutual trust and confidence and to promote effective implementation'. 
AAUs and CERs are legal abstractions of the various activities carried out by actors involved in their production and circulation. The nature and quality of these activities challenge the formal value of $1 \mathrm{Mt} \mathrm{CO}_{2}$ eq. assigned to them under the Kyoto Protocol. The analysis below will show that the mitigation value of the units depends mainly on the context of their first quantification (for carried-over AAUs) and on the type of mitigation project (for CERs).

\subsection{Legal Nature of AAUs and CERs and Their Associated Value(s)}

Legal commentaries on carbon markets do not converge on a single definition of tradable emission-allowance units, but rather identify their key features which reflect forms of attached value. Because any argument on the permissible use of such units depends, if only implicitly, on a theory of value, this section starts by tracing the linkages between legal conceptualizations of accounting units and related typologies of value, with a particular focus on AAUs and CERs.

The ways in which economic actors attribute value to commodities is a fundamental question of political economy. ${ }^{45}$ As tradable commodities, AAUs and CERs carry different forms of attached value, linked to what they formally represent and what they are used for. As noted, emission-accounting units in general represent an entitlement to release $1 \mathrm{Mt} \mathrm{CO}_{2}$ eq. into the atmosphere. This uniform format makes them fungible as well as usable for compliance under the Kyoto Protocol and other emission-trading schemes. ${ }^{46}$ Units have unique serial numbers containing information about their time of creation and, for offset credits, the offset project from which they originate. ${ }^{47}$ Given these characteristics, Streck sees in them a form of 'currency' built upon the idea of 'sameness' from a wide variety of activities that issue, or are issued

45 Frederick Harry Pitts, Value (Cambridge, UK: Polity, 2021).

46 Matthieu Wemaëre, Charlotte Streck, and Thiago Chagas, 'Legal Ownership and Nature of Kyoto Units and EU Allowances', in Legal Aspects of Carbon Trading: Kyoto, Copenhagen, and Beyond, edited by David Freestone and Charlotte Streck (Oxford: Oxford University Press, 2009), 37; James Munro, Emissions Trading Schemes under International Economic Law (Oxford: Oxford University Press, 2018), 31. Streck and Unger do not recognize the entitlement to emit for carbon-offset credits; see Charlotte Streck and Moritz von Unger, 'Creating, Regulating and Allocating Rights to Offset and Pollute: Carbon Rights in Practice', 10(3) Carbon and Climate Law Review 178 (2016), 179.

47 Munro, supra note 46,32 . 
with, emission allowances. ${ }^{48}$ Yet, these units are also generally divided into allowances issued to emission-trading schemes, on one hand, and offset credits created from baseline-and-credit mechanisms, on the other. In legal terms, the units are created either by regulatory schemes under international law or by those under national law, and can be mandatory or voluntary. ${ }^{49}$

This outline already begins to situate different yet co-existing domains of value attributed to Kyoto Protocol units. First, the fact that instruments of law or soft-law attribute to these units a standard, fixed amount of emissions ${ }^{50}$ may be understood as a manifestation of the 'formal', or face value of these units as a currency. Second, AAUs and CERs carry a 'use value' for their role in proving compliance. Third, as tradable commodities, they bear prices denominated in international currencies expressing their 'exchange value' between sellers and buyers. These last two forms of commodity value, which come from classical economics and Marxian traditions in political economy, ${ }^{51}$ have the benefit of shedding light on certain characteristics of value-attribution from social life (commodities have practical uses) and from the perception of the market (commodities are priced in currency). Formal value, instead, is an authoritative, fixed quantity of emissions attributed to a unit to ensure both utility and exchange.

The above three types of value-attribution are insufficient to reveal the role of complex social relations, activities, and material realities, that are themselves crucial factors in value-attribution - so crucial that they require a reconsideration of the value represented by the fixed, formal value at law. For instance, it is well known to those involved in the CDM in its early phase of implementation that it began as a scheme of non-additional, emission-increasing projects. ${ }^{52}$ This was the result of project participants proposing methodologies weak in additionality to suit their economic interests, which were accepted by the CDM Executive Board. This type of social reality had an impact on the value of CERs

48 Charlotte Streck, 'Who Owns REDD+? Carbon Markets, Carbon Rights and Entitlements to REDD+ Finance', 11(9) Forests 959 (2020), 965, citing the idea of 'sameness' from Donald MacKenzie, 'Making Things the Same: Gases, Emission Rights and the Politics of Carbon Markets', 34(3) Accounting, Organizations and Society 440 (2009).

49 Munro, supra note $46,32-42$.

50 For Kyoto Protocol units, see Kyoto Protocol, Decision 13/см P.1, Modalities for the accounting of assigned amounts under Article 7, paragraph 4, of the Kyoto Protocol, FCCC/ KP/CMP/2005/8/Add.2 (2006), Annex (hereinafter Decision 13/CMP.1).

51 Pitts, supra note 45, 20; Karl Marx, Capital Volume I: A Critique of Political Economy (London: Penguin Books, 1976), 125-6.

52 Michael Wara, 'Measuring the Clean Development Mechanism's Performance and Potential Symposium: Changing Climates: Adapting Law and Policy to a Transforming World', 55(6) UCLA Law Review 1759 (2007). 
in terms of price, but also in terms of formal value, given that those units did not reflect actual emission reductions. ${ }^{53}$

The consideration of the social dimensions of unit value formation borrows from value theories that look at the way in which institutions and social relations shape the value of commodities in general. ${ }^{54}$ Mirowski, a key proponent of a 'modern social theory of value', summarizes the rationale for looking at social dimensions it in this way: 'attributes of a commodity which are to be treated as relevant to market activity are themselves socially constructed.' 55 Thus, if assigned quantity, use, and price are only the apparent attributes of AAUs and CERs as intangible commodities, looking further into the social realities that give them their material form in emission-market registries throws further light on the value of these units.

As the field of view is expanded, an analysis of this kind comes with limitations and consequences. The main limitation is that one can never empirically assess with precision the extent to which the social events underlying the creation and circulation of units affect value. The main consequence is that social attributes challenge the fixity of formal value. The subsections below show that current legal interpretations of the nature of Kyoto Protocol units lack a coherent framework inclusive of the socio-political realities underlying their production. This, in turn, impedes a precise interpretation of their value and use under the Paris Agreement. However, an engagement with the critical literature on the political economy of carbon markets offers new elements for detailed legal arguments on unit transition.

\subsection{Beyond Formal Value and 'Sameness' of Units}

The legal scholarship addressing the nature of accounting units has considered in detail the realities that have troubled AAUs and CERs, ${ }^{56}$ as well as other units, ${ }^{57}$ and which are now threatening to affect the Article 6 mechanisms.

53 Ibid., $1781-5$, referring to a 'dilution of the CDM's currency, at least in terms of its environmental effectiveness'.

54 Pitts, supra note $45,74-99$.

55 Philip Mirowski, 'Learning the Meaning of a Dollar: Conservation Principles and the Social Theory of Value in Economic Theory', 57(3) Social Research 689 (1990), 709.

56 See for instance, Darragh Conway, 'Blazing Trail or Flickering Flame? Market Mechanisms under the UNFCCC', in Research Handbook on Climate Change Mitigation Law, edited by Geert van Calster, Wim Vandenberghe, and Leonie Reins (Cheltenham, UK: Edward Elgar Publishing, 2015), 425. More generally, see Michael Mehling, 'Between Twilight and Renaissance: Changing Prospects for the Carbon Market', 6(4) Carbon and Climate Law Review 227 (2012).

57 For instance, issues of carbon leakage linked to projects that generate carbon offsets in private voluntary carbon markets: Charlotte Streck, 'REDD+ and Leakage: Debunking Myths and Promoting Integrated Solutions', 21(6) Climate Policy 843 (2021). 
Yet, climate law scholars have focused on legal interpretations that put formal, use, and exchange value at the centre, while treating issues that challenge the comprehensiveness of these value-domains in expressing true value as being external to value-attribution. Such other factors are treated more as 'problems' to be at least partially overcome so to allow a reasonable realization of the market, ${ }^{58}$ or to make the mechanisms conform with due-process or rule-of-law requirements. ${ }^{59}$ The core of the debate on the legal nature of the units has instead been on whether they represent a mere nominal amount of $\mathrm{CO}_{2}$ eq. ${ }^{60}$ or are also an entitlement to emit that amount. ${ }^{61}$ When the social realities are included in value formation, the drawing of a coherent conceptual framework of qualitative distinctions becomes necessary, not only among different unit types, but also among units of the same type. But what exactly should be included from the social realm that challenges the notion that each AAU or CER represents $1 \mathrm{Mt} \mathrm{CO}_{2}$ eq.? Unlike in classical and Marxian political economy, labour is not the key social factor here. Instead, the focus is on the assemblage of political, technical, and socio-political events behind the legal construction of 'sameness' of AAUs and CERs. I will call these the 'constitutive events' of value, which encompass crucial vicissitudes in the chain of definition and issuance of these units. They encompass the technical and political dynamics of setting an emission cap and individual mitigation goals in emission-trading schemes and the socio-economic effects in implementing

$5^{8}$ For instance, price has been the fetish of legal design issues of the EU ETs. Thus, legal interpretations are tailored to interventions that would enable feasible prices of allowances, reflecting a more appropriate value. See, for instance, Carolyn Fischer, et al., 'The Legal and Economic Case for an Auction Reserve Price in the EU Emissions Trading System', 26(2) The Columbia Journal of European Law 1 (2020). See, however, Michael Mehling and Endre Tvinnereim, 'Carbon Pricing and the $1.5^{\circ} \mathrm{C}$ Target: Near-Term Decarbonisation and the Importance of an Instrument Mix', 12(1) Carbon and Climate Law Review 50 (2018), who also include 'binding political constraints' in the process of price formation, i.e. of exchangevalue attribution. Another example is carbon leakage from avoided deforestation projects, where different socio-economic drivers of deforestation would require tailored approaches to leakage avoidance; see Streck, ibid. On the tendency of legal scholarship to focus on the three realms of value see also Justin D. Macinante, Effective Global Carbon Markets: Networked Emissions Trading Using Disruptive Technology (Cheltenham, UK: Edward Elgar Publishing, 2020), and Michael Mehling, 'Legal Frameworks for Linking National Emissions Trading Systems', in The Oxford Handbook of International Climate Change Law, edited by Cinnamon Carlarne, Kevin R. Gray, and Richard Tarasofsky (Oxford: Oxford University Press, 2016), 257 .

59 Moritz von Unger and Charlotte Streck, 'An Appellate Body for the Clean Development Mechanism: A Due Process Requirement', 3(1) Carbon and Climate Law Review 31 (2009).

6o Benoit Mayer, The International Law on Climate Change (Cambridge, UK: Cambridge University Press, 2018), 115 .

61 Alexander Zahar, 'The Contested Core of Climate Law', 8(3-4) Climate Law 244 (2018), 256. 
emission-reduction projects, including the social and environmental impacts across local livelihoods, geographies, and ecosystems, as well as their actual contribution to global carbon mitigation.

To be sure, qualitative distinctions among units are not new to legal scholarship - but they are not conceptualized under a defined framework. ${ }^{62}$ For example, Macinante proposes a shift from a homogeneous to a heterogeneous understanding of valuing units, challenging the notion of a uniform formal value attributed to their different types. He argues this with reference to the hot-air AAUs issued during the first commitment period and to several events leading to the issuance of CERs. ${ }^{63}$ However, Macinante's heterogeneous approach ties the qualitative process of unit-value creation with the demandand-offer dynamics of the carbon market, including its financialization, and with the availability of transparent information related to each carbon unit. ${ }^{64}$ In other words, he challenges the formal value of units by relying on their exchange value. Such a focus explains the value of units only partially, as something dependent solely on the perceptions of market actors who enable price formation and exchanges in the market. But these units are also the product of underlying constitutive events engaged in by actors who are outside the market.

To inform a conceptual framework of value-attribution that goes beyond the market-based approach I turn to insights of the political economy literature on carbon markets. ${ }^{65}$ Critical studies in political economy have clarified the limits of neoclassical economic theory underpinning market-based mitigation

62 For instance, Conway, supra note 56, 429 notes the qualitative differences of AAUs transferred under the Green Investments Scheme.

63 Macinante, supra note 58.

64 Ibid., 62-6.

65 For instance, Emanuele Leonardi, 'Carbon Trading Dogma: Theoretical Assumptions and Practical Implications of Global Carbon Markets', 17(1) Ephemera: Theory and Politics in Organization 61 (2017); Larry Lohmann, 'Capital and Climate Change', 42 (2) Development and Change 649 (2011), 656; Matthew Paterson and Johannes Stripple, 'Virtuous Carbon', in The Politics of Carbon, edited by Benjamin Stephan and Richard Lane (Abingdon, UK: Routledge, 2015), 91; Steffen Böhm and Siddhartha Dabhi (eds.), Upsetting the Offset: The Political Economy of Carbon Markets (London: MayFly Books, 2009); Richard Lane and Peter Newell, 'The Political Economy of Carbon Markets', in The Palgrave Handbook of the International Political Economy of Energy, edited by Thijs Van de Graaf, et al., (London: Palgrave Macmillan, 2016), 247. The focus on 'constitutive events' here is related to Whitington's definition of a carbon market as 'an assemblage of agreements, conventional practices, durable artifacts and rules held among people who operate in very different contexts around the world': see Jerome Whitington, 'The Prey of Uncertainty: Climate Change as Opportunity', 12(1-2) Ephemera: Theory and Politics in Organization 113 (2012), 119. 
mechanisms. ${ }^{66}$ For instance, Leonardi argues that the carbon market hinges on a new form of value production based on knowledge-creation as a form of commodity, exchange, and financialization. ${ }^{67}$ This reconfiguration rejects the neoclassical notion of the market as a policy mechanism that reduces the aggregate abatement costs of emissions. ${ }^{68}$ Rather, the market is indifferent 'towards the concrete qualities that in other modes of wealth production are used to define objects' ${ }^{\prime} 9$ so that the formal value attributed to units of $1 \mathrm{Mt}$ $\mathrm{CO}_{2}$ eq. is entirely detached from any 'pre-existing' social need. As mere 'information', Leonardi claims that units only satisfy the needs of a market created by law favouring new forms of capital accumulation. Even if these units could indirectly satisfy the collective social need for carbon mitigation by their use for compliance purposes, Leonardi's view is still a good example of how the critical lens of political economy foregrounds fundamental inadequacies in what he calls the 'perfect carbon market' ideology. ${ }^{70}$ To explain the nature of units, Leonardi focuses on the creation of CERs. The key claim here, common to other works of this kind, ${ }^{71}$ is that proving the additionality of a CDM project involves a paradox, since the project developer must make the case to the CDM Executive Board that the project cannot finance itself without CERs, while, at the same time, the same developer must reassure investors of the solidity of the project's financial plan even in the absence of any support from the CDM. ${ }^{72}$ Therefore, as the product of a market mechanism created for capital accumulation and relying on a paradoxical assumption, CERs cannot represent truly additional emission reductions. ${ }^{73}$

This example of a key critique from the discipline of political economy challenges the assumption in the legal literature that the 'sameness' of units can be

66 For instance, Wemaëre, supra note 11, 150. For an overview and critiques of neoclassical economics see Navraj Singh Ghaleigh, 'Economics and International Climate Change Law', in Carlarne, et al. (eds.), supra note 58, 72; Sanja Bogojević, 'Ending the Honeymoon: Deconstructing Emissions Trading Discourses', 21(3) Journal of Environmental Law 443 (2009).

67 Leonardi, supra note 65,69 .

68 Ibid., 67.

69 Ibid., 74.

70 Leonardi, supra note 65, labels it the 'carbon market dogma'. 'Perfect' refers to the condition that 'no transaction costs' occur in the carbon market: see Ghaleigh, supra note 66.

71 See, for instance, Larry Lohmann, 'Regulation as Corruption in the Carbon Offset Markets', in Böhm and Dabhi (eds.), supra note 66, 175 .

72 Leonardi, supra note 65,76 .

73 See, on the contrary, Romain Felli, 'On Climate Rent', 22(3-4) Historical Materialism 251 (2014), 261, who correctly clarifies that Kyoto Protocol units have not created a private commodification of nature, as other critics have claimed, but a form of public property. 
guaranteed. ${ }^{74}$ Other examples may be given, but this one is sufficient for my purposes.

\section{Challenging the Formal Value of AAUs and CERS}

This section considers in more detail how constitutive events affect the formal value of AAUs and CERs for the purposes of their use under the Paris Agreement.

\subsection{AAUS}

An AAU's formal value of $1 \mathrm{Mt} \mathrm{CO}_{2}$ eq. is affected in the first place by the constitutive events leading to binding emission commitments for Annex B parties corresponding to overall mitigation goals for each commitment period. Those goals fell short of the required ambition under current mitigation pathways, namely pathways that have a good chance of keeping global warming within the limit of $1.5^{\circ} \mathrm{C}^{75}$ The AAUs issued to Annex B parties as their assigned amounts for a commitment period ${ }^{76}$ were primarily the result of consensus struck at the cops in Kyoto and Doha. They defined a priori the overall mitigation goal of each country for each period. Before reaching an international agreement, at the domestic level, technical assessments of baselines, reference scenarios, cost-benefit analyses, stakeholders' input, and other political processes, helped to determine the range of mitigation ambition that each Annex B party was prepared to commit to. This is what served as the basis for negotiating commitments under the Kyoto Protocol. ${ }^{77}$ However, the outcome of COP negotiations in Kyoto was a political compromise, which did not rely on transparent burden-sharing criteria among Annex B states. It essentially came

74 See Streck, supra note 48,8 , also recognizing that 'the creation of a tradable carbon currency faces ethical, methodological, and accounting barriers'.

75 Paris Agreement, art. 2(1)(a). See Navraj Singh Ghaleigh, 'Article 2: Aims, Objectives and Principles', in The Paris Agreement on Climate Change: A Commentary, edited by Geert Van Calster and Leonie Reins (Cheltenham, UK: Edward Elgar Publishing, 2021), 79, arguing that these targets where possible to be negotiated and defined because of the increased level of certainty from previous IPCC reports.

76 Decision 13/CMP.1, supra note 50, para. 23. The quantity of AAUs issued is calculated on agreed base-years and a compilation in a centralized database (see paras. $5^{-10}$ ).

77 For instance, the binding commitments of each EU member state in the Doha Amendment have resulted from technical and political exchanges which started with the EU Commission's initiative to set a 20 per cent emission-reduction commitment by 2020 . This target was the cornerstone of a comprehensive set of EU mitigation policies contained in a 'Climate Package', which was later reproposed in the EU commitment at the CMP in 
down to individual pledges, detached from IPCC assessments and without considering how the collective mitigation goal would actually contribute to the ultimate goal of the UNFCCC. ${ }^{78}$ Already this disconnect between the 'old' mitigation targets and the current scientifically informed mitigation pathways under the Paris Agreement affects the formal value of AAUs. This is because the Paris Agreement creates a new crucial element: a necessary link between the NDC process and the global warming limitation goal of Article 2, which translates into a global emission budget against which state emission targets are to be assessed. ${ }^{79}$

These constitutive events of value did not (or could not) take into account global mitigation pathways. What is more, the collective Annex B goal for the first commitment period was reduced by the hot air that some AAUs came to be identified with; and AAUs were further devalued by the overall increase in global emissions during the implementation of the Kyoto Protocol as a result of strong emission growth in emerging economies. Thus AAUs have lost considerable mitigation value over time even as they retained the formal value assigned to them under the Protocol. As a consequence, the claim that carried-over AAUs can be used to account for the implementation of NDCs is, at best, based on a distorted understanding of the nature and value of these units; at worst, it is reflective of bad faith in implementing the Paris Agreement.

\subsection{CERS}

The constitutive events of value-attribution for CERs are linked with an institutional and regulatory framework aimed at verifying the eligibility and performance of mitigation projects in developing countries. The CDM has faced problems with additionality, ${ }^{80}$ the negative local impacts of some projects

Doha, as agreed by the EU Council in its conclusions of 12 March 2012: see Council of the European Union, Follow-up to the 17th session of the Conference of the Parties (COP 17) to the UNFCCC and the 7 th session of the Meeting of the Parties to the Kyoto Protocol (CMP 7), Council Conclusions (9 March 2012), para. 12, <www.consilium.europa.eu/uedocs/cms_data/docs/ pressdata/en/envir/128882.pdf >. On the process that led to the EU Climate Package, see Elisa Morgera, Kati Kulovesi, and Miquel Munoz, 'Environmental Integration and Multi-Faceted International Dimensions of EU law: Unpacking the EU's 2009 Climate and Energy Package', 48(3) Common Market Law Review 829 (2011).

78 For the first commitment period, see Conway, supra note 56,428 .

79 Ghaleigh, supra note 75,8 o.

8o Axel Michaelowa, 'Interpreting the Additionality of CDM Projects', in Freestone and Streck (eds.), supra note 46, 248. For a sector-specific take on lack of additionality, see Philip M. 
(including human rights impacts and violations), ${ }^{81}$ and carbon leakage. ${ }^{82}$ The uneven geographical distribution of projects among developing countries also has been a source of criticism because LDCs and sub-Saharan countries in particular have benefited the least from CDM investment flows. ${ }^{83}$ Different value-domains of CERs are affected in different ways, depending on the issue and the related constitutive events.

Constitutive events that affect project additionality will affect formal value. The additionality requirement for a CDM project is met through a calculation of the project's potential to reduce or avoid emissions from a business-as-usual scenario and an assessment of whether the financial viability of the project depends on the receipt and sale of CERs. ${ }^{84}$ As is well known, additionality issues became vexed in certain projects involving unrealistic baselines. ${ }^{85}$ The gradual development of more-refined CDM methodologies and tools for calculating additionality might have improved precision, but once a baseline is accepted and the project is registered, it cannot be changed prior to the expiry of the crediting period. ${ }^{86}$ This is a problematic feature for projects that turn out to be non-additional during implementation.

These and other facets of the additionality problem take form through the complex constitutive events of a social ecosystem populated by a variety of

Fearnside, 'Tropical Hydropower in the Clean Development Mechanism: Brazil's Santo Antônio Dam as an Example of the Need for Change', 131(4) Climatic Change 575 (2015).

81 Wolfgang Obergassel, et al., 'Human Rights and the Clean Development Mechanism: Lessons Learned from Three Case Studies', 8(1) Journal of Human Rights and the Environment $5^{1}(2017)$.

82 Knut Einar Rosendahl and Jon Strand, 'Carbon Leakage from the Clean Development Mechanism', 32(4) The Energy Journal 27 (2011); Roland Geres and Axel Michaelowa, 'A Qualitative Method to Consider Leakage Effects from CDM and Ji Projects', 3o(6) Energy Policy 461 (2002).

83 Kristin Qui, The Future of the Clean Development Mechanism under a New Regime of Higher Climate Ambition, Environmental Defense Fund, 2018, <www.edf.org/sites/default/files/ documents/Potential_Supply_of_CDM_Credits.pdf>.

84 Michaelowa, supra note 80.

85 Michael Wara, supra note 52; Fearnside, supra note 80; Junjie Zhang and Can Wang, 'Co-Benefits and Additionality of the Clean Development Mechanism: An Empirical Analysis', 62(2) Journal of Environmental Economics and Management 140 (2011). For some projects this has also led to cases of skilful framing in order to receive as many CERs as possible while eroding project additionality. See Lohmann, supra note $71,180-2$. See also Alexander Zahar, International Climate Change Law and State Compliance (Abingdon, UK: Routledge, 2015), 146, finding that 'in practice [the CDM] is about encouraging the creation of more and more projects to reap the low-hanging fruit without unduly constraining investment or the flow of climate finance'.

86 Changes can be proposed by project participants, who have the least incentive to revise baselines to their disfavour. See: Executive Board of the CDM, CDM Project Standard for Project Activities (version 02.o), CDM-EB93-AO4-STAN, para. 227. 
actors: from project developers, to auditing entities; from national or subnational authorities in developing countries to local communities who are offered a period of open consultation for projects. ${ }^{87}$ The CDM Executive Board also affects the value of CERs with its regulatory and decisional competences over the entire mechanism, including project registration and issuance of units. ${ }^{88}$ For instance, in the CDM project cycle, all these actors perform many different activities: an accredited private entity validates a project for developers, before registering the activity under the mechanism; it later verifies and monitors the emission reductions of the project; a national authority confirms its participation by stating that the proposed project contributes to the 'sustainable development' of the host country. ${ }^{89}$ These constitutive events affect the formal value of CERs. For example, genuinely conservative baselines will generate CERs that have a higher formal value as they will have reduced emissions in the same amount as the CERs issued.

The local impacts of a project reflect the fact that projects are of many types and are nested in local geographies, each with their own social, political, and environmental realities. Thus, a project can yield a positive, neutral, or negative balance of local impacts. Some generate so called co-benefits, such as job creation, affordable access to energy, or more efficient access to and use of natural resources. ${ }^{90}$ But CERs also stem from projects with negative impacts: for instance, afforestation and reforestation projects have led to monoculture plantations with negative impacts on the livelihoods of small farmers; ${ }^{91}$ local people affected by large-scale hydropower projects have not benefited from the additional finance of the $\mathrm{CDM} ;{ }^{92}$ other projects have led to human rights violations or exclusion of local communities from decision-making. ${ }^{93}$

87 For an outline of the CDM 'project cycle' and its actors see Maria Netto and Kai-Uwe Barani Schmidt, 'The cDM Project Cycle and the Role of the UnCcc Secretariat', in Freestone and Streck (eds.), supra note 46,213 .

88 Kyoto Protocol, art. 12(4).

89 Kyoto Protocol, Decision 3/CMP.1, Modalities and procedures for a clean development mechanism as defined in Article 12 of the Kyoto Protocol, FCCC/KP/CMP/2005/8/Add.1 (2006), Annex, para. 40(a).

90 Nate Hultman, Jiehong Lou, and Stephen Hutton, 'A Review of Community Co-Benefits of the Clean Development Mechanism (CDM)', 15(5) Environmental Research Letters 053002 (2020).

91 Ashish Aggarwal, 'How Sustainable Are Forestry Clean Development Mechanism Projects?-A Review of the Selected Projects from India', 19(1) Mitigation and Adaptation Strategies for Global Change 73 (2014).

92 Jean-François Rousseau, 'Does Carbon Finance Make a Sustainable Difference? Hydropower Expansion and Livelihood Trade-Offs in the Red River Valley, Yunnan Province, China', 38(1) Singapore Journal of Tropical Geography go (2017).

93 Damilola S. Olawuyi, The Human Rights-Based Approach to Carbon Finance (Cambridge, UK: Cambridge University Press, 2016), 76-86. 
Unlike the issue of additionality, the CDM framework is unable to factor in ongoing positive or negative local impacts of projects and determine their consequences for CER issuance or value. Yet, constitutive events in the form of local impacts do affect the perceived value of CERs. Here CERs acquire or lose value in a way that cannot easily be translated into a change in their formal, use, or exchange values. ${ }^{94} \mathrm{Of}$ course, the decision about what value-forms will be given weight under the Paris Agreement has an ethical and political dimension. But it must also be informed by the principle of environmental integrity under Article 6 of the Paris Agreement, ${ }^{95}$ as well as the principles of accuracy, comparability, and consistency within the NDC accounting framework. ${ }^{96}$ Such a principled approach to considering CER value is needed to ensure a plausible level of 'sameness' between CERs and the other Article 6 units.

To give more substance to the claim made here that certain constitutive events affect the value of CERs, it is telling that the identification of eligibility criteria for the transition of CDM projects and the transfer of CERs under the Article 6.4 mechanism was a crucial issue that blocked the adoption of a CMA decision at COP $25 .{ }^{97}$ The last-ditch effort on a draft text by the UNFCCC Presidency could only arrive at a set of cut-off dates, i.e. a time-bound quantitative criterion, for the transition and use of pre-2020 CERs. ${ }^{98}$ Such an approach inevitably left the qualitative aspects affecting the value of CERs unaddressed; and so it frustrated the expectations of those parties seeking a broader inclusion of environmental integrity and other socio-legal aspects as conditions for transfer. ${ }^{99}$ It will be interesting to see whether qualitative aspects will in the end become part of the agreed eligibility criteria for the transfer of CERs.

94 This is the case even if market prices for CERs differ between credits stemming from 'high quality' projects and other CDM projects, as the labelling scheme of the Gold Standard exemplifies; see Gold Standard Foundation, 'Gold Standard for the Global Goals', 2019, <https://globalgoals.goldstandard.org/standards/101_V1.2_PAR_Principles-Requirements. pdf $>$.

95 Wemaëre, supra note 12 .

96 Paris Agreement, art. 4(13); Decision 18/CMA.1, supra note 30, para. 3.

97 Stephan Hoch, et al., Closing the Deal on CDM Transition: How COP25 Defined the Guardrails for Compromise and What they Mean for Africa, Climate Focus and Perspectives Climate Group, May 2020, <www.climatefinanceinnovators.com/wp-content/uploads/2020/05/ Closing-the-deal-on-CDM-Transition_web.pdf>.

98 Draft Text on Article 6.4 of the Paris Agreement, supra note 10, paras 72-6.

99 These have, instead, come to the fore during the negotiations on the rules, modalities, and procedures of the marked-based mechanism of Paris Agreement, art. 6(4). See San Jose Principles, supra note 9 . 
Toward a Conservative Use of Kyoto Protocol Units under the Paris Agreement

The complex process of increasing ambition in collective carbon-mitigation efforts under the Paris Agreement is facing a crucial test, as the pandemic has slowed down the pace of negotiations and the new cycle of NDCs is already proving slower to emerge and less ambitious than what is needed. ${ }^{100}$

The above analysis has argued for qualitative distinctions among the Kyoto Protocol units entering the Paris Agreement, with carried-over AAUs having a significantly lower value than their formal value of $1 \mathrm{Mt} \mathrm{CO}_{2}$ eq., and CERs holding different formal values depending on whether they originate in projects free of additionality concerns or negative local impacts. Thus, the value-attribution dynamics of these units must inform the eligibility criteria for their use under the Paris Agreement. The attainment of trust among parties requires these qualitative distinctions, both from individual states in deciding their reporting practice and from parties in order to arrive at specific norms to be included in future CMP/CMA decisions.

The transitioning of AAUs will have the effect of diminishing the ambition of NDCs, as one may assume that no party will have adopted an NDC that counts on previous 'overachievements' being carried over. It will also diminish ambition because the AAUs cannot represent $1 \mathrm{Mt} \mathrm{CO}_{2}$ eq. under the Paris Agreement, for the reasons given above. It is perhaps impossible to give an exact figure for the actual formal value of carried-over AAUs. But this is not critical: as their value is significantly diminished, Annex I countries should reject any form of reporting under the Paris Agreement that makes use of AAUs. To not do so would put countries at odds with the 'normative expectations' of ambition and progression under the Agreement; ${ }^{101}$ it would contradict the very principles of accounting for NDCs, which require the promotion of accuracy, comparability, and consistency; ${ }^{102}$ and, by reducing the ambition of NDCs, it will give rise to an inaccurate picture of mitigation effort and will make it even more difficult to compare effort across states.

A similar reasoning applies to the transition of CERs. As noted, CERs are qualitatively different from AAUs because their processes of value-attribution

\footnotetext{
100 At the time of writing Australia, Mexico, Brazil, Russia, Indonesia, Turkey, and Saudi Arabia have not submitted more ambitious revised targets for 2030; see Climate Action Tracker, 'Climate Summit Momentum: Paris Commitments Improved Warming Estimate to $2.4^{\circ} \mathrm{C}$ ', May 2021, 1, <https://climateactiontracker.org/documents/853/CAT_2021-05-04_ Briefing_Global-Update_Climate-Summit-Momentum.pdf>.

101 Rajamani and Brunnée, supra note 19.

102 Paris Agreement, art. 4(13); Decision 18/CMA.1, supra note 30, para. 3.
} 
differ considerably. In order to achieve an acceptable degree of environmental integrity and sound accounting, it will be necessary for states to patiently sift through CERs, possibly by a process set by a CMA decision. This must go beyond selection based on cut-off dates and vintage years. While this might require agreed qualitative criteria in the context of an MRV framework that does not exclude the use of CERs - and thus has the appearance of an uphill battleparties willing to rely on these offsets are nonetheless obliged to conform with the principles of NDC accounting, including environmental integrity, accuracy, comparability, and consistency. ${ }^{103}$ These entail practices of due diligence by states, consisting, for instance, in a careful vetting of their CER portfolios according to a mix of quantitative and qualitative criteria, such as geographical origin, scale, and proved co-benefits to local livelihoods. Unworthy CERs would be cancelled in state registries, while those kept could be considered eligible for NDC accounting and for the Article 6.4 mechanism. As required by the MRV framework, states will need to explain in their biennial reports the criteria and selection process they used for keeping CERs.

\section{Conclusion}

Reporting emissions and emission reductions under the international climate change regime is a difficult matter, made even more complex by the existence of Kyoto Protocol units and the future units that will be created under Article 6 of the Paris Agreement. This article offered a conceptual framework for a more comprehensive understanding of the valuing process behind units and it has shown some of the gaps in the legal scholarship. Framing these units as currencies, permits to emit, or proprietary assets fails to go to the heart of their value. Instead, looking at the vast range of value-attributing events by actors involved in the creation and use of these units reveals that there are important qualitative distinctions to be made among them.

A conceptual framework that is inclusive of social events that attribute value to commodities leads to legal arguments for a conservative use of Kyoto Protocol units under the Paris Agreement. But it can also offer tools for understanding important nuances in regulating and operating the future Article 6 mechanisms. It is still unclear whether IT Mos will rely on a single tradable unit of accounting, a plethora of different 'Iтмо allowances', or other indicators of

103 Ibid. 
'transferrable mitigation outcomes'. ${ }^{104}$ Still, complex social ecosystems undergirding the production and circulation of these units will also define crucial differences across Iт MOs and among project types under the Article 6.4 mechanism in such a way that the value of units will be affected. In responding to the impacts of these events, the Article 6 mechanisms could be designed with flexibilities that adjust the value of units (formal, use, or exchange). Challenging though it will be to put this into practice, a design of this kind is more likely to achieve high environmental integrity and sound accounting of NDCs than the traditional approach based on the fragile construct of 'unit sameness' and the ideology that the carbon market alone can lead to the most efficient mitigation outcomes. ${ }^{105}$

104 Wemaëre, supra note 11.

105 Thank you to Clemens Kaupa, Nicolas Kang-Riou, Anne Van Mulligen, Myele Rouxel, and to the two referees of the journal for their detailed comments on earlier versions of this article. I am also grateful to Pascale Bird and Christoph Schwarte of Legal Response Initiative for involving me in the legal query that prompted the research that led to this work. Any errors or omissions are of course my own. 